\title{
ANALISIS LINGKUNGAN INDUSTRI DAN FORMULASI STRATEGI: STUDI PENGEMBANGAN INSTITUSI RUMAH SAKIT
}

\author{
Dudi Permana \\ Fakultas Ekonomi Universitas Andalas Padang \\ e-mail: dudipermana.77@gmail.com \\ Niki Lukviarman \\ Fakultas Ekonomi Universitas Andalas Padang \\ e-mail: Lukviarman@yahoo.com
}

\begin{abstract}
The study aimed at analyzing the industry environment and its relationship to strategy formulation within the strategic management process in hospital strategic development process. As such the study identifies various factors related organizational environment from the view that hospital as the provider of public health services as well as providing facilities for educational and research for medical students. It may be argued that understanding of the hospital environment is of critical in formulating organizational strategy and determined the success of strategy implementation Both primary and secondary data were used to identify critical organizational environment as the foundation for strategy formulation process. The study recommends policy recommendation for hospital $X$ as follows; (a) enhancing research and development activities, $(b)$ efficient use of financial resources, (c) defined programs on human resources development. Furthermore, it is recommended that the hospital $X$ to utilized market penetration and product development strategies in its strategy.
\end{abstract}

Keywords: Organizational environment, Strategy formulation, Competitive advantage, Product Development, Market Penetration

\begin{abstract}
Abstrak
Studi ini bertujuan untuk menganalisis lingkungan industri dalam hubungannya dengan formulasi strategi sebagai bagian dari proses manajemen stratejik, di dalam pengembangan institusi rumah sakit. Identifikasi dilakukan terhadap berbagai faktor lingkungan industri rumah sakit, dengan karakteristik sebagai sektor publik yang tidak hanya melaksanakan fungsi pelayanan kesehatan masyarakat, namun juga mempunyai fungsi pendidikan dan penelitian. Dengan menggunakan data sekunder maupun primer terhadap Rumah Sakit X, dapat diidentifikasi berbagai hal terkait dengan lingkungan spesifik industri rumah sakit untuk penyusunan formulasi strategi. Studi ini merekomendasikan tiga hal terkait penguatan strategi Rumah Sakit X; (a) optimalisasi fungsi penelitian dan pengembangan, (b) efektifitas pengelolaan sumber daya keuangan, serta (c) program terstruktur terhadap pengembangan sumber daya manusia. Selanjutnya, direkomendasikan agar organisasi memilih strategi penetrasi pasar dan pengembangan produk.
\end{abstract}

Keywords; Lingkungan Industri, Formulasi Strategi, Keunggulan Kompetitif, Penetrasi Pasar

\section{PENDAHULUAN}

Rumah sakit adalah suatu organisasi yang unik dan kompleks karena merupakan institusi yang padat karya, mempunyai sifat dan ciri serta fungsi khusus dalam pelayanan penderita. Andaleeb (1998) berpendapat bahwa salah satu industri sektor publik yang tumbuh dengan cepat adalah industri perawatan kesehatan atau rumah sakit. Disamping melaksanakan fungsi pelayanan kesehatan masyarakat, rumah sakit juga mempunyai fungsi pendidikan dan penelitian (Boekitwetan, 1997).

Peran institusi rumah sakit dewasa ini semakin dituntut untuk memberikan pelayanan yang lebih bermutu dan sanggup memenuhi berbagai kebutuhan yang diakibatkan oleh berbagai perubahan epidemiologi penyakit, struktur sosial dan ekonomi, perkembangan ilmu dan 
teknologi dan struktur demografis. Dengan alasan demikian maka rumah sakit tidak dapat dikelola dengan manajemen yang sederhana, tetapi harus dikelola secara profesional sehingga mampu memenuhi kebutuhan masyarakat yang muncul akibat perubahan tersebut. Untuk menjawab tantangan persaingan rumah sakit dimasa yang akan datang, disamping organisasi harus menciptakan jasa dan produk baru dengan menggunakan teknologi terkini, inovatif dan kreatif, organisasi yang fleksibel dan mudah beradaptasi (Ayuningtyas et al., 2005).

Laporan Dinas Kesehatan RI pada tahun 2009 mengungkapkan bahwa di Sumatera Barat berjumlah 44 buah, dengan rincian 17 unit RSU milik Pemerintah, 24 unit merupakan RS Swasta serta 3 unit RS TNI/POLRI. Sementara untuk wilayah Kota Padang, sebagai ibukota propinsi dan dengan jumlah penduduk terbanyak, jumlah Rumah Sakit sebanyak 24 buah (3 unit RSU milik pemerintah, 19 unit RS Swasta, dan 2 unit RS TNI/POLRI). Terkonsentrasinya rumah sakit di Kota Padang membawa konsekuensi semakin tajamnya persaingan di lingkungan industri rumah sakit daerah tersebut, namun dengan kondisi tersebut konsumen mempunyai pilihan yang semakin banyak untuk jasa rumah sakit yang mereka inginkan.

Rumah Sakit X (selanjutnya disingkat RS "X") adalah salah satu rumah sakit swasta yang berlokasi di Kota Padang dan berada diatas tanah $2500 \mathrm{~m}^{2}$. RS "X" memiliki gedung seluas $5.000 \mathrm{~m} 2$, yang terdiri dari Gedung Perawatan Blok A berlantai 3 dan Blok B berlantai 5 untuk menunjang 52 tempat tidur pelayanan medis, serta penunjang medis dan Gedung Blok C Instalasi Rawat Jalan. Dari segi unit pelayanan, RS "X" memiliki unit rawat inap, unit rawat jalan dan unit gawat darurat. Dari ketiga unit layanan yang dimiliki, maka unit rawat inap merupakan unit bisnis unggulan RS " $X$ " yang perlu dilakukan pengembangan kedepan.

Kotler (2000) berpendapat bahwa faktor penentu keberhasilan didalam menjalankan usaha adalah produk/pelayanan, harga, promosi dan tempat. Adapun produk yang diberikan kepada klien oleh rumah sakit adalah berupa produk jasa (Lestari, 2004). Sementara itu harga menjadi pertimbangan orang untuk memilih rumah sakit, karena harga merupakan jumlah uang yang dibutuhkan untuk mendapatkan sejumlah kombinasi dari produk pelayanan (Kotler, 2000). Dengan demikian dapat dinyatakan bahwa antara harga dan pelayanan memiliki hubungan yang kuat. Berdasarkan hal tersebut para pelaku pelayanan dengan produk jasa dituntut untuk meningkatkan mutu pelayanannya secara prima, jika ingin mendapatkan tempat dalam pasar yang makin dewasa (Permana, 2002).

Berdasarkan hasil strategic mapping yang dilakukan (lihat gambar 1), maka penelitian ini mengambil dua rumah sakit pesaing sebagai benchmark dalam mengidentifikasi lingkungan industri dan rekomendasi strategi, karena dianggap sebagai pesaing terdekat bagi RS "X". Alasan selanjutnya adalah bahwa kedua pesaing tersebut memiliki tipe yang sama dengan RS "X" yaitu rumah sakit swasta dan setara rumah sakit tipe $\mathrm{D}$ sesuai dengan ketetapan Direktur Jenderal Pelayanan Medik Departemen Kesehatan RI. Untuk keperluan penentuan posisi RS "X" dalam strategic mapping digunakan faktor harga dan pelayanan untuk unit rawat inap dalam, sebagaimana dapat dilihat pada gambar 1 .

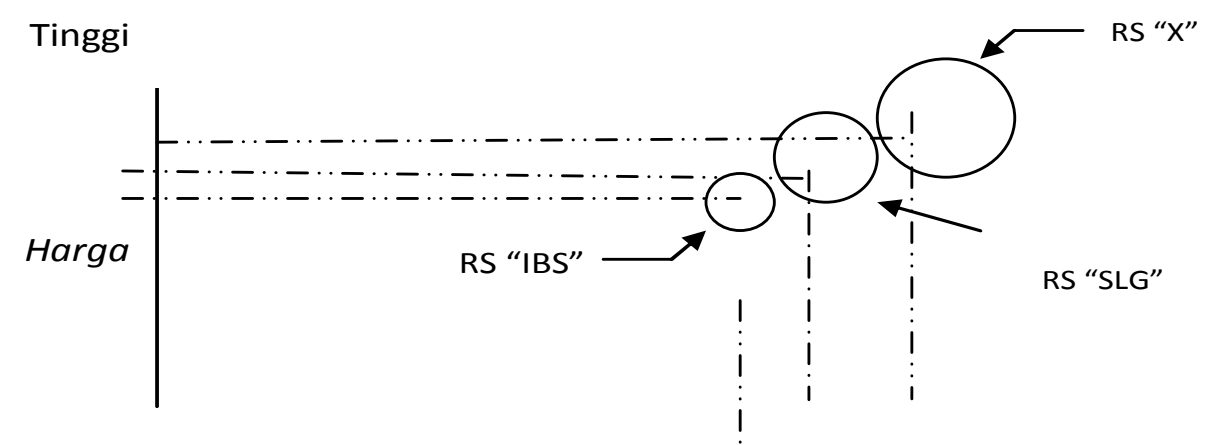

Rendah

Kualitas Pelayanan

Tinggi

Gambar 1: Strategic Mapping Unit Rawat Inap RS "X" 
Dari ilustrasi di atas dapat disimpulkan bahwa RS "X" dari segi pelayanan dan harga berada pada posisi paling tinggi dibanding dengan pesaing terdekatnya RS "SLS" dan pesaing lainnya RS "IBS". Dari segi fasilitas unit rawat inap RS "X" adalah rumah sakit yang terbaik dibanding dengan dua rumah sakit pesaingnya. Dengan dasar demikian maka RS "X" selayaknya mempersiapkan strategi pengembangan strategi yang sesuai dengan karakteristik organisasi tersebut, untuk menghadapi persaingan industri rumah sakit khususnya unit rawat inap. Berdasarkan hal tersebut maka RS "X" harus memilih dan mempunyai rencana strategi bisnis untuk menghadapi persaingan dalam jangka panjang serta menjaga keberlangsungan hidup institusi tersebut.

Berdasarkan uraian dari latar belakang sebagaimana dijelaskan di atas maka tulisan ini akan mengevaluasi dan merekomendasikan strategi bisnis yang dapat digunakan oleh Unit Rawat Inap Rumah Sakit X untuk menghadapi persaingan dalam jangka panjang. Dengan demikian, maka penelitian ini bertujuan untuk (a) mengidentifikasi berbagi faktor lingkungan internal dan eksternal Unit Rawat Inap RS "X" dalam menghadapi persaingan bisnis saat ini, (b) mengidentifikasi strategi bisnis yang telah dijalankan saat ini oleh Unit Rawat Inap RS "X", dan (c) merumuskan strategi terpilih bagi Unit Rawat Inap RS "X" untuk menghadapi persaingan dalam jangka panjang. Pembahasan difokuskan terhadap berbagai faktor yang mempengaruhi penentuan alternatif strategi yang dapat diterapkan sesuai dengan karakteristik organisasi tersebut. Alternatif strategi terpilih dan strategi yang direkomendasikan diharapkan dapat digunakan untuk mencapai visi dan misi RS "X"

\section{KAJIAN PUSTAKA Definisi Strategi}

Strategi berasal dari bahasa Yunani kuno yang berarti "seni berperang". Secara umum strategi dapat diartikan sebagai rencana yang berskala besar dan berorientasi dengan lingkungan persaingan dalam mencapai tujuan perusahaan. Sementara itu Rangkuti (2002) menyatakan bahwa strategi merupakan tindakan yang bersifat incremental (senantiasa meningkat) dan terus menerus serta dilakukan berdasarkan sudut pandang tentang apa yang diharapkan oleh para pelanggan dimasa depan.

Manajemen strategi didefinisikan sebagai suatu seni dan ilmu untuk memformulasi, implementasi dan evaluasi keputusan-keputusan fungsional yang memungkinkan organisasi mencapai tujuannya (David, 2005). Definisi dari manajemen strategis bermakna sebagai suatu usaha memfokuskan manajemen untuk saling terintegrasi antara unit yang terlibat dalam organisasi, seperti pemasaran, keuangan/akuntansi, produk/operasi, penelitian pengembangan, serta sistem informasi untuk mencapai kesuksesan dan tujuan organisasi. Pendapat yang sama juga dikemukakan oleh Pearce and Robinson (2007) bahwa manajemen strategi adalah sekumpulan keputusan dan tindakan yang dapat menghasilkan suatu perumusan dan pelaksanaan rencana yang dirancang untuk mencapai sasarn organisasi. Dengan demikian maka manajemen strategi sangat menentukan keberhasilan suatu bisnis atau organisasi dalam mencapai tujuan organisasi.

Berkaitan dengan hal tersebut Soejitno (2000) berpendapat bahwa pengembangan rumah sakit, perlu mengacu kepada: 1) Filosofi rumah sakit mengacu pada adagium lama bahwa pasien dan keluarganya adalah pelanggan yang wajib dipuaskan. 2) Dalam menggali dana kemanusiaan, rumah sakit perlu untuk merencanakan suatu program public relation dan pemasaran sosial yang sistematis. 3) Budaya atau citra rumah sakit perlu dijaga agar menjadi suatu institusi yang sosial dan masih harus dibantu. 4) Pelatihan staf harus dilakukan secara sistematis dalam mengantisipasi terhadap berbagai kemungkinan adanya perubahan. 5) Apabila diversikasi mampu dilakukan rumah sakit diluar bisnisnya intinya.

Berdasarkan uraian di atas dapat disimpulkan bahwa institusi rumah sakit tidak bisa terlepas sebagai institusi yang bersifat sosial yang membutuhkan peningkatan kompetensi karyawan, kegiatan pemasaran dan diversifikasi bisnis harus dilakukan dalam rangka peningkatan kualitas dan kepuasan pelanggan.

\section{Lingkungan Industri}

Lingkungan yang mempengaruhi proses bisnis rumah sakit seperti yang dinyatakan Soejitno (2000) dapat diilustrasikan melalui gambar 2. Berdasarkan ilustrasi tersebut dapat disimpul- 
kan bahwa lingkungan organisasi rumah sakit dipengaruhi oleh lingkungan langsung dan lingkungan tak langsung. Lingkungan langsung terdiri dari mitra dalam dan mitra luar, mitra dalam merupakan lingkungan internal organisasi sendiri yang terlibat langsung dalam kegiatan operasional rumah sakit. Sedangkan mitra luar terdiri dari kelompok masyarakat maupun lembaga-lembaga yang mendukung kegiatan operasional organisasi rumah sakit, tetapi mereka berada diluar lingkungan organisasi rumah sakit. Sementara yang dimaksudkan dengan lingkungan tidak langsung adalah lingkungan sosial, teknologi, ekonomi dan politik (Pearce and Robinson, 1997). Semua variabel tersebut tidak dapat dikontrol perubahannya oleh organisasi rumah sakit. Dalam kaitannya dengan penyusunan strategi, organisasi hanya bisa memprediksi atau meramalkan kondisi semua variabel tersebut dimasa yang akan datang.

\section{Keunggulan Kompetitif}

Keunggulan bersaing merupakan suatu kondisi yang menggambarkan kinerja sebuah perusahaan relatif terhadap pesaing dalam hal product marketing (Peteraf and Bearney, 2003). Penelitian tentang keunggulan kompetitif merupakan salah satu penelitian inti dalam manajemen strategik. Dalam beberapa dekade, berbagai penelitian dengan perspektif teori yang berbeda terus dikembangkan untuk menjelaskan bagaimana sebuah perusahaan mampu mengembangkan strategi bersaing dibandingkan pesaingnya. Cara pandang tersebut antara lain; pencapaian posisi keunggulan bersaing superior (Bain, 1956, 1959; Porter, 1980; 1985; 1998), membangun dan mencapai sumber daya strategik superior (Amit and Schoemaker, 1993; Barney, 1986, 1991; Peteraf, 1993; Wernerfelt,
1984), serta kemampuan dalam mengatur kembali sumber daya organisasi menjadi sumber daya yang strategis dan bernilai (Eisenhardt and Martin, 2000; Teece, Pisano and Shuen, 1997). Sementara pandangan baru tentang konsep keunggulan bersaing seperti yang diungkapkan oleh Bettis and Hitt (1995) menunjukkan bahwa bentuk kompetisi yang terjadi pada berbagai macam industri saat ini menekankan kepada fleksibilitas, kecepatan dan inovasi dalam merespon perubahan lingkungan yang cukup dinamis. Namun demikian, yang perlu menjadi perhatian adalah bahwa dalam upaya membangun keunggulan kompetitif, sebuah organisasi tidak terlepas dari kekuatan kunci lingkungan eksternal dan internal.

Kekuatan kunci eksternal dapat dibagi menjadi lima kategori (David, 1997) yaitu kekuatan ekonomi; kekuatan sosial, budaya, demografi; kekuatan politik, peraturan pemerintah dan hukum; teknologi, serta kekuatan pesaing. Sementara kekuatan kunci internal dapat dibagi menjadi enam kategori yaitu manajemen, pemasaran, produksi dan operasi, penelitian dan pengembangan, keuangan/akunting, serta sistem informasi. Dalam perspektif yang sama, Duncan (1995) menambahkan faktor budaya dan citra organisasi sebagai faktor kunci internal sebuah organisasi.

Menurut David (2005) terdapat tiga tahapan yang harus dilalui dalam menentukan alternatif strategi pilihan tersebut. Adapun tahapan tersebut adalah tahap diagnosis/input stage, tahap penggabungan/matching stage dan tahap penerapan strategi/decision stage. Lebih lanjut, Duncan (1995) memberikan penekanan perlunya analisis terhadap visi dan misi organisasi dalam rencana pengembangan sebuah organisasi.

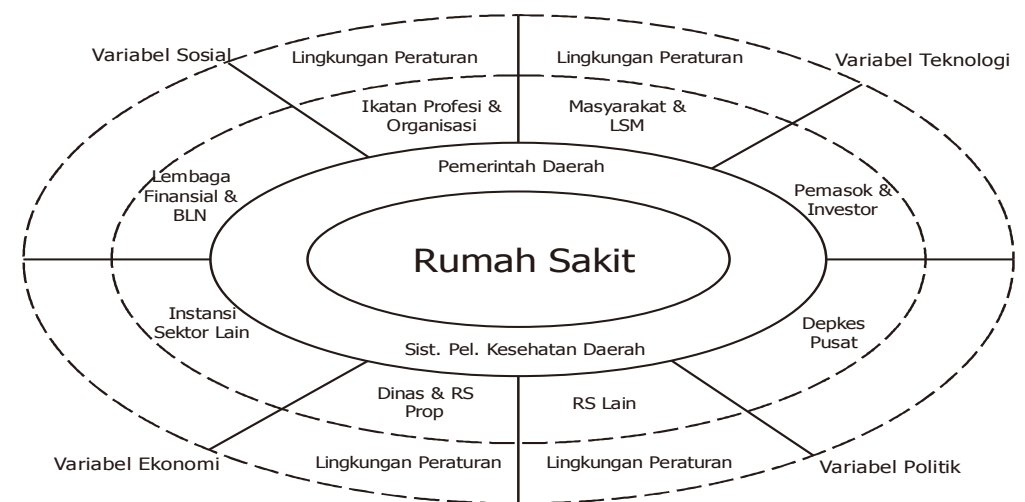

Gambar 2: Lingkungan Organisasi Rumah Sakit (Soejitno, 2000) 


\section{Kerangka Berpikir}

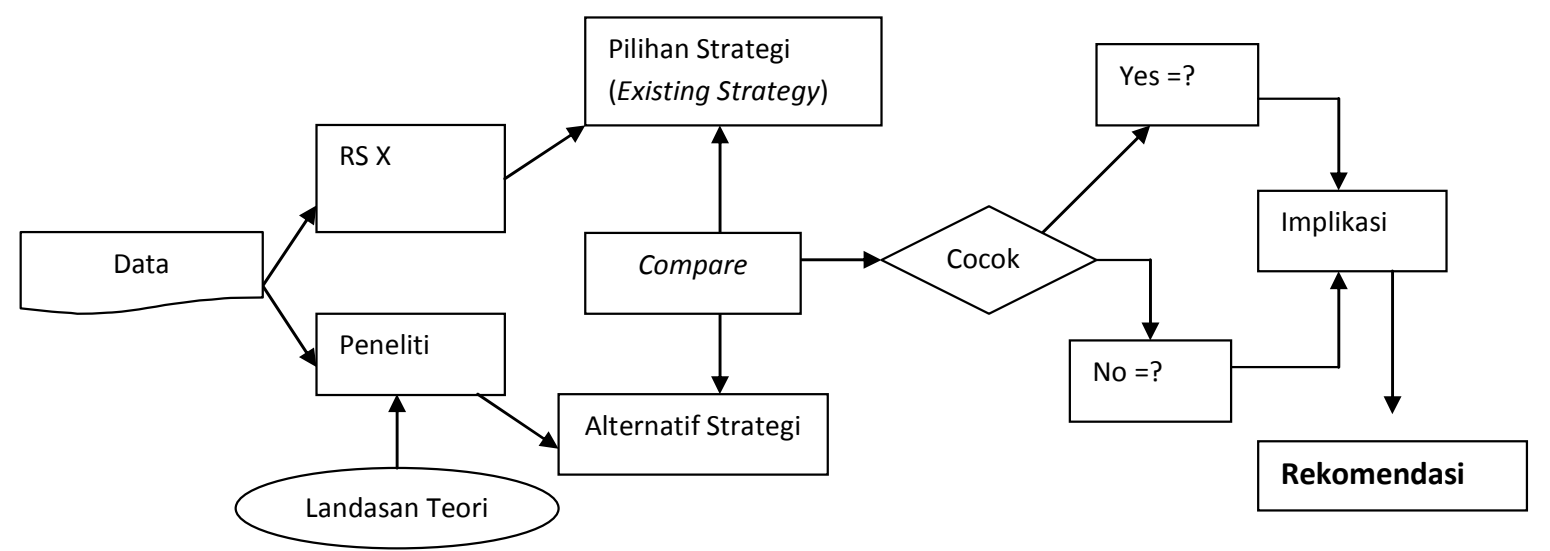

Gambar 3: Kerangka Berfikir

\section{METODE PENELITIAN}

Tulisan ini dilakukan berdasarkan penelitian yang bersifat penelitian eksploratif (exploratory research), meliputi penelitian deskriptif (descriptive research) namun ditambahkan dengan memberikan rekomendasi (Sekaran, 2000). Dalam penelitian ini digunakan dua jenis data yaitu data sekunder dan data data primer. Data Sekunder diperoleh dari Bagian Rekam Medik dan Bagian Keuangan RS X dan Badan Pusat Statistik, dan Dinas Kesehatan Tingkat I Sumatera Barat, Tingkat II Kodya Padang. Sedangkan Data Primer diperoleh melalui hasil wawancara mendalam (indepth interview) dengan Direktur Utama RS X dan hasil wawancara dengan Direktur SDM, Kepala Rumah Sakit, manajer keuangan dan materi RS "X" yang selanjutnya disebut Concencus Decision Making (CDM).

Analisis terhadap data yang relevan dengan keperluan analisis lingkungan eksternal dan internal diharapkan menemukan peluang dan ancaman terhadap lingkungan eksternal, serta kekuatan dan kelemahan faktor lingkungan internal RS "X". Menurut David (2005) terdapat tiga tahapan yang harus dilalui untuk menentukan alternatif strategi pilihan tersebut; (a) tahap diagnosis/input stage, (b) tahap penggabungan/matching stage, dan (c) tahap penerapan strategi/decision stage.

\section{Tahap Input (Input Stage)}

Pada tahap input dilakukan perhitungan secara subjektif sebagai tahap awal dari perumusan strategi. Hasil perhitungan adalah berupa pembuatan keputusan kecil dalam matriks input menyangkut kepentingan relatif dari berbagai faktor eksternal dan internal, sehingga dapat dihasilkan dan dievaluasi strategi secara lebih efektif. Penilaian intuitif yang baik selalu diperlukan dalam menetapkan pembobotan dan penilaian yang tepat. Dalam kaitan ini tahap input terdiri dari: 1) Analisis Lingkungan Usaha Internal (IFE), yaitu alat perumusan strategi yang berguna untuk mengevaluasi kekuatan dan kelemahan utama dalam berbagai bidang fungsional dari suatu usaha. 2) Analisis Lingkungan Usaha Eksternal (EFE), yaitu alat perumusan strategi untuk meringkas dan mengevaluasi informasi ekonomi, sosial, budaya, demografi, politik, pemerintah, hukum, teknologi dan persaingan.

\section{Tahap Pencocokan (Matching Stage)}

Pada tahapan pencocokan digunakan matrik Threat-Opportunity-Weakness-Strength

(TOWS matrix) dan matrik Internal External (I-E matrix), sebagaimana tampak pada Gambar 4. Matrik IE dibagi menjadi tiga bagian utama yang mempunyai strategi yang berbeda (David, 1997). Pertama, divisi atau unit bisnis yang termasuk ke dalam sel I, II, IV, dinamakan pada posisi Growth and Build dan strategi yang tepat untuk dilakukan pada divisi atau unit bisnis ini adalah strategi intensif atau integratif. Strategi intensif dapat dilakukan dengan penetrasi pasar, pengembangan produk dan pengembangan pasar, sedangkan strategi integratif dapat dilakukan dengan integrasi kedepan, integrasi kebelakang dan integrasi horizontal. Kedua, divisi atau unit bisnis yang termasuk ke dalam sel III, V, VII, dinamakan pada posisi hold and maintain, penetrasi pasar 
dan pengembangan pasar merupakan dua strategi yang terbanyak dilakukan untuk divisi ini.

\section{Tahap Pengambilan Keputusan (Decision Stage)}

Pada tahapan pengambilan keputusan (decision stage) digunakan matrix QSPM (Quantitative Strategic Planning Matrix). Dalam pembuatan keputusan formulasi strategi ini didasari oleh analisa dan kebijakan intuisi. Pada analisa penyesuaian atau pencocokan (matching) hanya menyatakan alternatif strategi yang layak saja tetapi belum dilakukan prioritas pilihan strategi. Beberapa strategi tambahan yang dihasilkan dari analisa penyesuaian (matching) hanya menyatakan alternatif strategi yang layak. Tabel 1 berikut menunjukkan contoh format QSPM.

\begin{tabular}{|c|c|c|}
\hline IFAS & Kekuatan- S & Kelemahan-W \\
\hline Peluang-O & $\begin{array}{c}\text { STRATEGI (SO) } \\
\text { Future Quadrant }\end{array}$ & $\begin{array}{c}\text { STRATEGI (WO) } \\
\text { Internal Fix-it Quadrant }\end{array}$ \\
\hline Ancaman-T & $\begin{array}{c}\text { STRATEGI (ST) } \\
\text { External Fix-it Quadran }\end{array}$ & $\begin{array}{c}\text { STRATEGI (WT) } \\
\text { Survival Quadrant }\end{array}$ \\
\hline
\end{tabular}

Gambar 4: Matrik TOWS (David, 2005)

\begin{tabular}{cc|c|c|c|}
\multirow{2}{*}{} & 400 & \multicolumn{2}{c}{300} & \multicolumn{2}{c}{200} & 100 \\
\cline { 3 - 5 } & & I & II & III \\
\cline { 3 - 5 } EFAS & 300 & IV & V & VI \\
\cline { 3 - 5 } & 200 & VII & VIII & IX \\
\cline { 3 - 5 } & 100 & & &
\end{tabular}

Gambar 5. Matrik Internal-Eksternal (David, 2005)

Tabel 1: Contoh Format QSPM (Daved, 2005)

\begin{tabular}{|c|c|c|c|c|}
\hline Faktor Kunci & Bobot & $\begin{array}{l}\text { Alternatif } \\
\text { Strategi } 1\end{array}$ & $\begin{array}{l}\text { Strategi } \\
\text { Strategi } 2\end{array}$ & Strategi 3 \\
\hline \multicolumn{5}{|l|}{ Faktor Eksternal } \\
\hline 1. Ekonomi & & & & \\
\hline \multicolumn{5}{|l|}{ 2. Politik/Peraturan } \\
\hline \multicolumn{5}{|l|}{ Pemerintahan } \\
\hline \multicolumn{5}{|l|}{ 3. Sosial/Budaya/Demografi/ } \\
\hline \multicolumn{5}{|l|}{ Lingkungan } \\
\hline \multicolumn{5}{|l|}{ 4. Teknologi } \\
\hline \multicolumn{5}{|l|}{ 5. Kompetisi } \\
\hline \multicolumn{5}{|l|}{ Faktor Internal } \\
\hline \multicolumn{5}{|l|}{ 1. Manajemen } \\
\hline \multicolumn{5}{|l|}{ 2. Pemasaran } \\
\hline \multicolumn{5}{|l|}{ 3. Keuangan/Akuntansi } \\
\hline \multicolumn{5}{|l|}{ 4. Penelitian Pengembangan } \\
\hline 5. Sistem Informasi & & & & \\
\hline
\end{tabular}




\section{HASIL ANALISIS Analisis Tahap Input}

Berdasarkan hasil analisis lingkungan eksternal perusahaan, selanjutnya faktor peluang dan ancaman dimasukkan kedalam matriks External Factor Evaluation (EFE Matrix) tampak pada tabel 2. Hasil pada tabel 2 menunjukkan bahwa bahwa faktor peluang perusahaan lebih besar dibandingkan dengan faktor ancaman. Hal ini berdasarkan nilai yang nilai sub total dari faktor peluang (nilai 1,80 ) lebih besar dari nilai sub total faktor ancaman (nilai 1,10). Sementara itu hasil analisis lingkungan internal dimasukkan kedalam Internal Factor Evaluation Matrix tampak pada tabel 3.

Tabel 2: External Factor Evaluation Matrix

\begin{tabular}{|c|c|c|c|c|}
\hline $\begin{array}{l}\text { Faktor-faktor } \\
\text { Strategi Ekternal }\end{array}$ & Kode & Bobot & Rating & $\begin{array}{c}\text { Bobot } \\
\mathbf{x} \\
\text { Rating }\end{array}$ \\
\hline Peluang & & \multirow{2}{*}{0,09} & \multirow{2}{*}{3} & \multirow{2}{*}{0,27} \\
\hline 1. Jumlah penduduk dan angkatan kerja Sumbar dan Padang & & & & \\
\hline 2. Kelompok umur dan pendidikan pasien rawat inap RS "X" & B & 0,10 & 3 & 0,30 \\
\hline 3. Cara pembayaran pasien rawat inap RS "X" & $\mathrm{C}$ & 0,12 & 3 & 0,36 \\
\hline $\begin{array}{l}\text { 4. Kinerja pelayanan rawat inap RS "X" dibanding rumah sakit } \\
\text { pesaing }\end{array}$ & $\mathrm{D}$ & 0,12 & 4 & 0,48 \\
\hline 5. Dukungan pemasok & $\mathrm{E}$ & 0,13 & 3 & 0,39 \\
\hline Sub Total & & & & 1,80 \\
\hline Ancaman & & & & \\
\hline \multirow{5}{*}{$\begin{array}{l}\text { 1. RKU penduduk Sumbar dan Kodya Padang tinggi } \\
\text { 2. Pendapatan perkapita regional Sumbar dan Padang masih rendah } \\
\text { 3. Pengeluaran biaya rumah tangga dan kesehatan penduduk Sumbar } \\
\text { dan Padang Masih rendah } \\
\text { 4. Kebijakan pemerintah mengenai otonomi daerah } \\
\text { 5. Kebijakan pemerintah mencabut subsidi BBM dan impor bahan } \\
\text { baku obat, kenaikan TDL }\end{array}$} & $\mathrm{F}$ & 0,10 & 3 & 0,30 \\
\hline & $\mathrm{G}$ & 0,07 & 3 & 0,21 \\
\hline & $\mathrm{H}$ & 0,09 & 3 & 0,27 \\
\hline & I & 0,08 & 2 & 0,16 \\
\hline & $\mathrm{J}$ & 0,08 & 2 & 0,16 \\
\hline \multirow{2}{*}{\multicolumn{2}{|c|}{ Sub Total }} & & & 1,10 \\
\hline & & & & 2,90 \\
\hline
\end{tabular}

Tabel 3: Internal Factor Evaluation Matrix

\begin{tabular}{|c|c|c|c|c|}
\hline Faktor -faktor Strategi Internal & Kode & Bobot & Rating & $\begin{array}{l}\text { Bobot } x \\
\text { Rating }\end{array}$ \\
\hline \multicolumn{5}{|l|}{ Kekuatan } \\
\hline 1. Telah memiliki visi dan misi & A & 0,09 & 2 & 0,18 \\
\hline $\begin{array}{l}\text { 2. Citra dan nama baik telah terbina dengan baik dan diakui } \\
\text { pemerintah. }\end{array}$ & B & 0,09 & 3 & 0,27 \\
\hline $\begin{array}{l}\text { 3. Fasilitas fisik berdasarkan lokasi, bangunan serta prasarana } \\
\text { relatif baru }\end{array}$ & $\mathrm{C}$ & 0,09 & 3 & 0,27 \\
\hline 4. Produk pelayanan memilki kinerja cendurung meningkat & $\mathrm{D}$ & 0,10 & 2 & 0,20 \\
\hline $\begin{array}{l}\text { 5. Sistem informasi pelayanan pasien sudah terintegrasi dengan } \\
\text { LAN }\end{array}$ & $\mathrm{E}$ & 0,09 & 2 & 0,18 \\
\hline Sub Total & & & & 1,11 \\
\hline Kelemahan & & & & \\
\hline 1. SDM, secara kualitas masih rendah, turn over cukup tinggi. & $\mathrm{F}$ & 0,11 & 3 & 0,33 \\
\hline 2. Keuangan jangka pendek kurang baik & G & 0,10 & 2 & 0,18 \\
\hline 3. Struktur organisasi masih terkotak kotak & $\mathrm{H}$ & 0,10 & 3 & 0,30 \\
\hline 4. Belum jalannya penelitian dan pengembangan & I & 0,12 & 4 & 0,48 \\
\hline 5. Pemasaran belum tertata dengan baik & $\mathrm{J}$ & 0,14 & 3 & 0,42 \\
\hline Sub Total & & & & $\begin{array}{l}1,70 \\
2,81\end{array}$ \\
\hline
\end{tabular}


Hasil perhitungan pada tabel 3 di atas menunjukkan bahwa hasil analisis lingkungan internal menunjukkan bahwa faktor kelemahan perusahaan (nilai 1,70) perusahaan lebih besar dibandingkan dengan faktor kekuatan (nilai $1,11)$.

\section{PEMBAHASAN}

\section{Analisis Tahap Pencocokan}

\section{Matrix TOWS}

Hasil penilaian terhadap yang dirangkum dalam bentuk TOWS matrix dapat dilihat pada gambar 6 pada halaman berikut. Pada tahapan matching antara pengaruh faktor lingkungan eksternal dan internal dilakukan penilaian dengan Internal External Matrix. Berdasarkan penilaian $\operatorname{EFE}(2,90)$ dan IFE $(2,81)$ maka bagian rawat inap RS "X" berada pada sel V (hold and maintain) pada IE Matrix, seperti dapat dilihat pada gambar 7 .

Berdasarkan analisis yang tergambar melalui Internal External Matrix diatas dapat dilihat bahwa RS " $\mathrm{X}$ " berada pada sel V.
Strategi untuk organisasi yang berada pada sel $\mathrm{V}$ IE Matrix adalah posisi hold and maintain, strategi terbanyak yang dilakukan oleh organisasi pada posisi ini menurut David (2005) adalah melakukan dua alternatif strategi yaitu penetrasi pasar (market penetration) dan pengembangan produk (product development). Apabila dilakukan pencocokkan dengan matriks TOWS maka kondisi tersebut berada pada strategi WO atau Internal Fix-it Quadrant yaitu menciptakan strategi yang meminimalkan kelemahan dan memanfaatkan peluang yang ada.

\section{Tahap Pengambilan Keputusan (Decision Stage)}

Berdasarkan matriks Internal Eksernal diatas maka didapatkan alternatif strategi terpilih yaitu penetrasi pasar dan pengembangan produk. Dari dua alternatif strategi tersebut selanjutnya dilakukan pemilihan prioritas strategi dengan melakukan tabulasi prioritas strategi seperti yang dapat dilihat pada tabel 4 .

\begin{tabular}{|c|c|c|}
\hline $\begin{array}{l}\text { IFAS } \\
\text { EFAS }\end{array}$ & $\begin{array}{l}\quad \text { STRENGTHS }(\boldsymbol{S}) \\
\text { 1. Visi dan misi } \\
\text { 2. Citra dan nama baik } \\
\text { 3. Fasilitas Fisik } \\
\text { 4. Produk Pelayanan } \\
\text { 5. Sistem Informasi Manajemen }\end{array}$ & $\begin{array}{l}\text { WEAKNESSES }(\boldsymbol{W}) \\
\text { 1. SDM } \\
\text { 2. Keuangan } \\
\text { 3. Struktur Organisasi } \\
\text { 4. Penelitian dan Pengembangan } \\
\text { 5. Pemasaran }\end{array}$ \\
\hline $\begin{array}{l}\text { OPPORTUNITIES }(\boldsymbol{O}) \\
\text { 1. Jumlah penduduk angkatan kerja daerah Padang dan } \\
\text { Kerja } \\
\text { 2. Kelompok umur dan pendidikan pasien rawat inap } \\
\text { RSU "XYZ" } \\
\text { 3. Cara pembayaran pasien rawat inap RSU "XYZ" } \\
\text { 4. Kinerja pelayanan rawat inap RSU "XYZ" } \\
\text { dibandingkan dengan rumah sakit pesaing } \\
\text { 5. Dukungan pemasok }\end{array}$ & $\begin{array}{l}\text { STRATEGI (SO) } \\
\text { 1. Mempertajam visi dan misi } \\
\text { 2. Mempertahankan dan } \\
\text { meningkatkan citra dan nama baik } \\
\text { 3. Meningkatkan kinerja pelayanan }\end{array}$ & $\begin{array}{l}\quad \text { STRATEGI }(\text { WO }) \\
\text { 1. Memberdayakan divisi } \\
\text { penelitan dan } \\
\text { pengembangan } \\
\text { 2. Melakukan analisa } \\
\text { keuangan dan biaya } \\
\text { terhadap unit rawat inap } \\
\text { 3. Meningkatkan kompetensi } \\
\text { SDM }\end{array}$ \\
\hline $\begin{array}{l}\text { TREATHS }(\boldsymbol{T}) \\
\text { 1. RKU penduduk Sumbar dan Padang tinggi. } \\
\text { 2. Pendapatan perkapita regional Sumbar dan Padang } \\
\text { masih rendah } \\
\text { 3. Pengeluaran biaya rumah tangga dan kesehatan } \\
\text { penduduk Sumbar dan Padang masih rendah } \\
\text { 4. Kebijakan pemerintah mengenai otoda } \\
\text { 5. Kebijakan pemerintah mencabut subsidi BBM dan } \\
\text { impor bahan baku obat-obatan serta kenaikan TDL }\end{array}$ & $\begin{array}{l}\text { STRATEGI (ST) } \\
\text { 1. Menyempurnakan Sistem } \\
\text { Informasi Manajemen } \\
\text { 2. Melakukan perencanan } \\
\text { keuangan kedepan } \\
\text { 3. Memilih produk pelayanan } \\
\text { unggulan }\end{array}$ & $\begin{array}{l}\text { STRATEGI }(\boldsymbol{W T}) \\
\text { 1. Melakukan pembenahan } \\
\text { dibidang internal khusunya } \\
\text { SDM } \\
\text { 2. Menyediakan pelayanan } \\
\text { sesuai dengan kemampuan } \\
\text { masyarakat }\end{array}$ \\
\hline
\end{tabular}

Gambar 6: TOWS Matrix

\begin{tabular}{|c|c|c|}
\hline I & II & III \\
\hline IV & RSU "X" (hold and maintain) & VI \\
\hline VII & VIII & IX \\
\hline
\end{tabular}

Gambar 7: Internal External Matrix 
Tabel 4: QSPM Prioritas Strategi

\begin{tabular}{|c|c|c|c|c|c|}
\hline \multirow{3}{*}{ Faktor Kunci } & \multirow{3}{*}{ Bobot } & \multicolumn{4}{|c|}{ Alternatif Strategi } \\
\hline & & \multicolumn{2}{|c|}{ Market Penetration } & \multicolumn{2}{|c|}{ Product Development } \\
\hline & & $\mathbf{A S}$ & TAS & $\mathbf{A S}$ & TAS \\
\hline \multicolumn{6}{|l|}{ Kekuatan } \\
\hline 1. Visi dan misi & 0,09 & 4 & 0,36 & 4 & 0,36 \\
\hline 2. Citra dan nama baik & 0,09 & 4 & 0,36 & 4 & 0,36 \\
\hline 3. Fasilitas fisik & 0,09 & 3 & 0,27 & 4 & 0,36 \\
\hline 4. Produk pelayanan & 0,10 & 4 & 0,40 & 4 & 0,40 \\
\hline 5. Sistem Informasi Manajemen & 0,09 & 4 & 0,36 & 3 & 0,27 \\
\hline \multicolumn{6}{|l|}{ Kelemahan } \\
\hline 1. SDM & 0,11 & 4 & 0,44 & 4 & 0,44 \\
\hline 2. Keuangan & 0,10 & 3 & 0,30 & 4 & 0,40 \\
\hline 3. Struktur Organisasi & 0,10 & 3 & 0,30 & 3 & 0,30 \\
\hline 4. Penelitian dan pengembangan & 0,12 & 4 & 0,48 & 4 & 0,48 \\
\hline 5. Pemasaran & 0,14 & 4 & 0,56 & 4 & 0,56 \\
\hline \multicolumn{6}{|l|}{ Peluang } \\
\hline 1. Jumlah penduduk dan angkatan kerja & 0,09 & 4 & 0,36 & 3 & 0,27 \\
\hline 2. Umur dan pendidikan pasien & 0,10 & 4 & 0,40 & 4 & 0,40 \\
\hline 3. Cara pembayaran Rawat Inap & 0,12 & 3 & 0,36 & 3 & 0,36 \\
\hline 4. Kinerja pelayanan & 0,12 & 4 & 0,48 & 4 & 0,48 \\
\hline 5. Dukungan pemasok & 0,13 & 3 & 0,39 & 3 & 0,39 \\
\hline \multicolumn{6}{|l|}{ Ancaman } \\
\hline 1. RKU penduduk & 0,10 & 4 & 0,40 & 4 & 0,40 \\
\hline 2. Pendapatan perkapita penduduk & 0,07 & 4 & 0,28 & 4 & 0,28 \\
\hline 3. Pengeluaran RT dan kesehatan & 0,09 & 4 & 0,36 & 4 & 0,36 \\
\hline 4. Otonomi daerah & 0,08 & 2 & 0,16 & 2 & 0,16 \\
\hline 5. Pencabutan subsidi BBM, Impor, TDL & 0,08 & 2 & 0,16 & 3 & 0,24 \\
\hline Jumlah & & & 7,18 & & 7,27 \\
\hline
\end{tabular}

Berdasarkan hasil QSPM, maka prioritas strategi terpilih dengan Total Attractiveness Score (TAS) 7,27 adalah pengembangan produk atau product developmnet. Dalam kaitan ini, pengembangan produk merupakan strategi untuk meningkatkan penjualan dengan jalan memperbaiki atau memodifikasi produk atau jasa yang ada.

Berdasarkan analisis yang telah dilakukan untuk memperoleh rekomendasi strategi bisnis pada Unit Rawat Inap RS " $X$ " maka dapat disimpulkan beberapa hal berikut: Pertama, berdasarkan hasil analisis pada tahap input (input stage) dengan menggunakan matriks EFE dan IFE maka diperoleh hasil analisis dengan nilai EFE $(2,90)$ dan nilai IFE $(2,81)$.

Kedua, ada tahap pencocokan (matching stage) dengan menggunakan matrik TOWS, hasil analisis mengindikasikan bahwa RS " $\mathrm{X}$ " berada pada posisi WO (Internal-Fix It Quadrant). Posisi ini merekomendasikan 3 (tiga) strategi yaitu; (a) memberdayakan divisi penelitian dan pengembangan, (b) melakukan analisa keuangan dan biaya terhadap unit rawat inap, dan (c) meningkatkan kompetensi SDM. Kesimpulan ini diambil berdasarkan hasil perolehan nilai EFE dan IFE memperlihatkan bahwa faktor kelemahan $(1,70)$ lebih besar dari kekuatan $(1,11)$ dan faktor peluang $(1,80)$ lebih besar dari ancaman $(1,10)$. Apabila dilakukan pencocokkan dengan matriks TOWS maka kondisi tersebut berada pada strategi WO atau Internal Fix-it Quadrant yaitu menciptakan strategi yang meminimalkan kelemahan dan memanfaatkan peluang yang ada (David, 1997).

Ketiga, pada tahap pencocokan (matching stage) dengan menggunakan matriks Internal-Eksternal maka unit rawat inap RS " $\mathrm{X}$ " berada pada sel V (hold and maintain). Posisi tersebut merekomendasikan alternatif strategi penetrasi pasar (market penetration) dan pengembangan produk (product development).

Keempat, pada tahap keputusan (decision stage) melalui QSPM Prioritas Strategi menghasilkan rekomendasi strategi bisnis untuk RS " $\mathrm{X}$ " adalah pengembangan produk (product development), hal ini berdasarkan 
hasil analisisi melalui QSPM Prioritas strategi yang menghasilkan nilai TAS (Total Attractiveness Score) untuk alternatif strategi pengembangan produk $(7,27)$ lebih besar dari TAS untuk alternatif strategi penetrasi pasar $(7,18)$.

Kelima, Untuk tindak lanjut strategi direkomendasikan kepada manajemen RS "X" untuk melakukan strategi pengembangan produk (product development) dengan melakukan pembenahan internal berdasarkan hasil analisa matriks TOWS yang menunjukkan RS "X" berada pada posisi WO. Jadi pada tahap tindak lanjut strategi penulis merekomendasikan perusahaan untuk menjalankan strategi pengembangan produk (product development) dan melakukan pembenahan internal dengan jalan memberdayakan divisi penelitian dan pengembangan, melakukan analisa keuangan dan biaya terhadap unit rawat inap dan meningkatkan kompetensi SDM.

\section{Implikasi Praktikal}

Pemilihan strategi pengembangan produk sangat sesuai dengan kondisi organisasi saat ini dengan beberapa alasan berikut: Pertama, Organisasi mempunyai produk yang menjadi unggulan dan dalam tahap pematangan dalam menarik pelanggan seperti tergambar dari tujuan khusus RS "X" yaitu; menjadikan RS "X" sebagai Rumah Sakit Swasta rujukan, khususnya bidang kebidanan dan penyakit kandungan di Sumatera Tengah. Dari tujuan khusus tersebut dapat disimpulkan bahwa RSU "X" fokus dengan produk unggulannya dalam bidang kebidanan dan penyakit kandungan.

Kedua, Organisasi bersaing dalam industri dengan pertumbuhan yang tinggi. Berdasarkan analisa lingkungan eksternal yang dilakukan maka ancaman dari organisasi adalah semakin tumbuhnya bisnis sejenis di Kota Padang khususnya dan didukung oleh kebijaksanaan pemerintah yang memberikan kemudahan prosedur pendirian Rumah Sakit dan klinik dalam rangka menuju "Indonesia Sbat".

Ketiga, pesaing utama menawarkan produk dengan harga yang bersaing. Berdasarkan stategic mapping tergambar bahwa pesaing terdekat RS "X" yaitu RS "SLG" mememilliki penawaran harga yang lebih kompetitif dengan tingkat pelayanan yang sedikit lebih rendah dibandingkan dengan RS "X". Oleh sebab itu RS "X" harus melakukan strategi pengembangan produk untuk memenuhi keinginan pelanggan saat ini agar dapat mengantisipasi pesaing terdekatnya tersebut. Hal ini juga sesuai dengan tujuan khusus dari organisasi yaitu meningkatkan mutu pelayanan RS "X" dengan berorientasi kepada keinginan dan kepuasan pelanggan.

Sementara itu faktor yang kurang mendukung strategi ini adalah kondisi internal organisasi, karena berdasarkan analisa lingkungan internal yang dilakukan terdapat indikasi bahwa organisasi lemah dalam riset dan pengembangan. Hal ini dapat disebabkan karena faktor Sumber Daya Manusia yang kurang mendukung, sedangkan tujuan khusus keempat RS "X" adalah meningkatkan mutu dan kinerja SDM di lingkungan RS "X". Berdasarkan dua kondisi tersebut terdapat kontradiksi antara rencana strategi yang dijalankan perusahaan saat ini dengan rencana strategi bisnis yang direkomendasikan.

Hasil matriks TOWS mempelihatkan bahwa organisasi berada pada strategi $W O$ atau internal fix-it quadrant yaitu strategi yang meminimalkan kelemahan dan memanfaatkan peluang yang ada. Berdasarkan hasil tersebut maka strategi terpilih product development pada RS " $X$ " dapat dilakukan melalui strategi WO hasil dari TOWS matriks yaitu; (a) memberdayakan divisi atau bagian penelitian dan pengembangan, dan (b) melakukan analisa keungan dan biaya terhadap unit rawat inap dan ketiga, meningkatkan kompetensi SDM.

Untuk memberdayakan divisi atau bagian penelitian dan pengembangan dapat ditindaklanjuti dengan dengan cara: 1) memasukkan divisi atau bagian penelitian dan pengembangan pada struktur organisasi. 2) menyusun program dan melakukan rekruitmen pelaksana divisi atau bagian penelitan dan pengembangan serta melibatkan seluruh unsur dari tiap bagian dalam kelompok kerja penelitian dan pengembangan. 3) melakukan penelitian dan pengembangan dengan memanfaatkan data internal dan eksternal dalam rangka meningkatkan pelayanan kepada pelanggan serta melibatkan seluruh sumber daya yang ada. 4) menindaklanjuti setiap hasil penelitian yang dilakukan apabila hasil tersebut bermanfaat terhadap kemajuan perusahaan. 5) membina kerjasama dengan pihak universitas 
dalam bidang penelitian dan pengembangan tersebut.

Selanjutnya perlu dilakukan analisa keuangan dan biaya terhadap unit rawat inap dapat dilakukan dengan cara: 1) menghitung dan menetapkan biaya jasa pelayanan yang ada saat ini atau akan ditawarkan serta menyesuaikan biaya tersebut dengan kemampuan pelanggan untuk membayar. 2) melakukan penelitian dan perencanaan anggaran keuangan secara tepat. 3) menggalang komitmen dan supervisi terhadap pelaksanaan rencana anggaran. 4)meningkatkan kemampuan dan keterampilan pelaksana manajemen keuangan.

Sementara itu dalam hal meningkatkan kompetensi SDM dapat ditindaklanjuti dengan cara: 1) Menyempurnakan struktur organisasi sehingga semua komponen organisasi dapat menjalankan tugasnya sesuai dengan tugas dan tanggung jawabnya. 2) Menganalisa dan menyempurnakan job description terutama untuk level manajer dan staf. 3) Menyusun program kerja bagian SDM. 4) Melakukan survey untuk mengetahui harapan dan keinginan SDM baik yang berhubungan dengan motivasi, kompensasi dan pengembangan karir mereka. 5) Meningkatkan kompetensi SDM melalui pendidikan dan pelatihan melalui lembaga pendidikan formal atau informal.

Dengan menjalankan strategi product development pada RS "X" diharapkan mampu memberikan pelayanan yang lebih baik dengan harga atau biaya yang lebih bersaing khususnya untuk unit rawat inap RS "X" dengan terus melakukan pembenahan terhadap internal organisasi. Selanjutnya disarankan untuk dilakukan evaluasi terhadap implementasi strategi pengembangan terhadap unit rawat inap ini, dengan jalan melakukan survey terhadap para staf dan karyawan RS "X" terutama yang pekerjaannya berhubungan langsung dengan unit rawat inap. Sementara itu untuk meningkatkan kualitas pelayanan perlu dilakukan survey dan analisa kepuasan pelanggan khususnya terhadap unit rawat inap RS "X". Dengan demikian, maka manajemen RS "X" akan mengetahui bentuk pelayanan yang dinginkan oleh pelanggan, sehingga hal tersebut akan menjadi catatan dan koreksi bagi manajemen untuk melakukan penataan terhadap kualitas pelayanan khususnya untuk unit rawat inap.

\section{PENUTUP}

Penelitian ini berkontribusi dalam pengembangan studi bidang manajemen stratejik pada institusi rumah sakit, namun masih memiliki 3 (tiga) keterbatasan. Pertama, penelitian ini bersifat penelitian studi kasus pada satu rumah sakit. Sehingga hasil penelitian ini tidak bisa digeneralisir seluruhnya untuk institusi rumah sakit lainnya.Kedua, analisis pada penelitian ini menggunakan matriks IFE, EFE dan TOWS yang dominan menggunakan perspektif para pengambil keputusan strategis, sehingga unsur subjektifitas cukup dominan. Hal ini merupakan salah satu keterbatasan dalam menggunakan matriks tersebut dalam melakukan analisis strategi. Ketiga, implikasi praktikal penelitian ini baru berada pada tatanan formulasi strategi dan belum mendetailkan dalam bentuk program kegiatan.

Untuk penelitian selanjutnya diharapkan mampu memberikan implikasi praktikal yang lebih detail sampai dengan tatanan program kegiatan.

\section{DAFTAR PUSTAKA}

Amit, R. and PJH. Schoemaker. 1993. Strategic Assets and Organizational Rent. Strategic Management Journal. 14. 33-46.

Andaleeb, SS. (1998). Determinants of customer satisfaction with hospitals: a managerial model. Internatioanl Journal of Health Care Quality Assuranec. 181-187.

Ayuningtyas, D. dan S. Tambunan. 2005. Penilaian Mutu Rumah Sakit Tugu Ibu dengan the Malcolm Balbridge National Quality Award Tahun 2005. Jurnal Manajemen Pelayanan $\mathrm{Ke}$ sehatan.Universitas Indonesia. 8 (4).

Barney, J.B. 1986. Strategic Factor markets: Expectations, Luck and Business Strategy. Management Science. 32. 1231-1241.

Barney, JB. 1991. Firm Resources and Sustained Competitive advantage. Journal of Management. 17. 99-120.

Bain, JS. 1956. Barrier to New Competition. Harvard University Press. 
Bain, JS. 1959. Industrial Organization. New York. Wiley.

Bettis, RA. and MA. Hitt. 1995. The New Competitive Landscape. Strategic Management Journal. 16 (Special Issue). 7-19

Boekitwetan P. 1997. Pemahaman rekam medik rumah sakit. Majalah Ilmiah FK Universitas Trisakti. 16 (7). 1675-1685

David, FR. 2005. Strategic Management: Concept and Cases. Tenth Edition. Prentice Hall

Duncan, JW. 1996. Strategic Management of Health Care Organizations, Second Edition. Blackwell Business Publishers Inc.

Eisenhardt, KM. and JA. Martin. 2000. Dynamic capabilities: What are they? Strategic Management Journal. 21. 1105-1121.

Kotler, P. 2000. Marketing Millenium: Analisis, Perencanaan, Implementasi dan Kontrol. Jilid Satu. PT Prenhallindo.

Lestari, TRP. 2004. Pemasaran Pelayanan Kesehatan di Rumah Sakit Sebagai Upaya Menciptakan Image Positif Masyarakat. Jurnal Manajemen Administrasi Rumah Saki. Jakarta. UI.

Pearce, JA. and RB. Robinson. 2007. Strategic Management: Formulation, Implementation, and Control. Tenth Edition. McGraw Hill.
Permana, HS. 2002. Konsep Modal Rumah Sakit Era Otonomi Pelayanan Kesehatan. Artikel Marsi. Jakarta. UI.

Peteraf, MA. 1993. The Cornerstones of Competitive Advantage: a Resource-Based View. Strategic Management Journal. 14. 179-191.

Porter, ME. 1980. Competitive Strategy New York. Free Press

Porter, ME. 1985. Competitive Advantage. New York. Free Press

Porter, ME. 1998. Keunggulan Bersaing: Menciptakan dan Mempertahankan Kinerja Unggul. Edisi Bahasa Indonesia, Binarupa Aksara Jakarta.

Rangkuti, F. 2002. Analisis SWOT Teknik Membedah Kasus Bisnis. Gramedia Pustaka Utama.

Sekaran, U. 2000. Research Methods For Business, Third Edition, John Wiley and Sons, Inc.

Soejitno, S. 2000. Reformasi Perumahsakitan Indonesia. Jakarta. Hastarimasta.

Teece, DJ., G. Pisano. and A. Shuen. 1997. Dynamic Capabilities and Strategic Management. Strategic Management Journal. 18. 509-533.

Wernerfelt, B. 1984. A resource-based view of the firm. Strategic Management Journal. 5. 171-180. 